\title{
A POLÍTICA E A CULTURA DO “CONTENTAMENTO" NO PROCESSO DA GLOBALIZAÇÃO
}

The politics and culture of "contentment" in the globalization process

Jair Inácio Tauchen*

Resumo: O presente artigo tem a intenção de desenvolver uma crítica à política e à cultura do "contentamento", expressão cunhada por John Kenneth Galbraith, cujo sistema econômico está ancorado no laissez faire, no compromisso da desregulamentação do mercado. Na política do contentamento, a democracia é para atender os favorecidos e satisfeitos, priorizando o imediatismo e a acomodação do pensamento político e econômico. Os afortunados não agem considerando o longo prazo, o esforço está centrado no contentamento imediato, na acumulação do capital. O que se vislumbra para o futuro é a manutenção de uma boa renda para os ricos e, por outro lado, a conservação da pobreza aos pobres. Para acabar com essa cultura é fundamental envolver as ações do estado afim de corrigir a situação atual de fuga da realidade e se tornar igualmente necessário, tanto para os satisfeitos como para os excluídos e à margem.

Palavras-chave: Contentamento; política; cultura; democracia.

\begin{abstract}
This article aims to develop a critique of the politics and the culture of "contentment", which is an expression coined by John Kenneth Galbraith, whose economical system relies on laissez faire and on the commitment to the deregulation of the market. In the politics of contentment, democracy is made to serve those who are favored and satisfied, so that immediatism and the accommodation of political and economical thought are prioritized. The lucky ones do not act on the long run, their effort is focused on the immediate contentment, on the accumulation of the capital. What they expect from the future is the preservation of a good income for the rich and, inversely, the perpetuation of the poorness for the poor. In order to break with this culture, it is indispensable to involve the action of the State with the aim of correcting the actual situation of escape from reality and creating a situation where the state is equally necessary for the fortunate ones as well as for the people who are excluded and marginalized.
\end{abstract}

Keywords: Contentment; policy; culture; democracy.

\footnotetext{
* Doutorando em Filosofia pela Pontifícia Universidade Católica do Rio Grande do Sul, bolsista CAPES. E-mail: jairtauchen@gmail.com.
}

\begin{tabular}{|c|c|l|l|l|l|}
\hline intuitio & $\begin{array}{c}\text { ISSN } \\
1983-4012\end{array}$ & Porto Alegre & Vol.11- $\mathrm{N}^{\circ} .1$ & $\begin{array}{l}\text { Julho } \\
2018\end{array}$ & p.105-114 \\
\hline
\end{tabular}


O presente artigo tem a intenção de apresentar e desenvolver uma crítica referente a política e a cultura do "contentamento", expressão cunhada por John Kenneth Galbraith ${ }^{1}$ na obra A cultura do contentamento, que servirá de referência e base para o presente texto. A cultura do contentamento, inicialmente, tem sua âncora no laissez faire, ou seja, no compromisso da desregulamentação do mercado. Conforme essa doutrina, a intervenção do governo e, sobretudo, a regulamentação governamental, é vista como desnecessária além de prejudicial ao processo da globalização estabelecido. Porém, o caráter do compromisso é altamente seletivo, que poderá ser percebido no decorrer da exposição. Aos olhos da cultura do contentamento, é importante salientar, sempre que houver o sumiço do dinheiro, quando a crise se instalar no mercado, e, somente nesses casos, a responsabilidade para encontrar a solução recai sobre o estado.

Quando, ao longo do processo histórico, surgem importantes questões a serem ponderadas, no primeiro momento, não é aconselhável e nem prudente aceitá-las de imediato, sem questionamento. O mesmo vale para a vida das pessoas e, sobretudo, para a questão econômica e política, que sofrem um contínuo processo de transformações, podendo a mesma ação ou evento, apresentar diferentes resultados. Na economia americana, por exemplo, o colapso do mercado de ações de 1929 provocou a falência dos bancos, a ruína dos investidores, interferindo em toda a cadeia econômica, evento conhecido como a experiência da Grande Depressão. Outro marco histórico, o colapso de 1987, provocou estrago e trauma no mercado, no entanto, com menor destruição econômica. Nesse espaço de tempo uma série de medidas públicas foram incorporadas à economia americana, muitas delas com garantia governamental. Entre as principais garantias estão os depósitos bancários, os pagamentos da previdência, os subsídios aos preços agrícolas. O curioso é que os beneficiários dessas classes econômicas e políticas atribuem o sucesso e eficácia àquilo que elas próprias usufruem. Na verdade, o que está por trás dessa política econômica, é um implícito compromisso governamental de não permitir a falência das grandes corporações industriais e bancárias. Grupos de privilegiados que se beneficiam de pujantes e eficazes facilidades econômicas e políticas, com o intuito de prolongar o contentamento porque, para o mercado, tudo aquilo que agrada e tranquiliza, resulta em mais dinheiro.

Esse processo não cessou aí. É do conhecimento geral que os grandes empreendedores, principalmente através do fenômeno da globalização, continuaram a comandar a vida política e econômica da Grã-Bretanha, Alemanha, França, Estados Unidos nos séculos XIX, XX e até a atualidade. Essas

\footnotetext{
${ }^{1}$ John Kenneth Galbraith (1908 - 2006) foi um economista, filósofo e escritor estadunidense, que ficou conhecido por suas posições keynesianas e, também, pelo seu estilo liberal-social. Foi assessor econômico do presidente John Kennedy, autor de mais de 40 livros, entre os quais de maior destaque The Affluent Society (A sociedade Opulenta), A era das incertezas, A fraude inocente: o crescimento das grandes empresas e o futuro da democracia.
}

\begin{tabular}{|c|c|c|c|c|c|}
\hline intuitio & $\begin{array}{c}\text { ISSN } \\
1983-4012\end{array}$ & Porto Alegre & Vol.11 $-\mathrm{N}^{\circ} .1$ & $\begin{array}{l}\text { Julho } \\
2018\end{array}$ & p.105-114 \\
\hline
\end{tabular}


corporações não esboçaram nenhum constrangimento ou sentimento de culpa pelo acúmulo do capital, diante da sofrida classe trabalhadora que trocava sua força de trabalho pela subsistência.

Esses abusos foram percebidos por todos, provocando a ira na população, especialmente na primeira década do século XX. Por exemplo, na tentativa de aliviar a situação, o ministro da fazenda Lloyd George da Grã-Bretanha, promoveu um programa de assistência aos desamparados e aos desempregados, provocando uma violenta resistência por parte dos afortunados. Atualmente, a maioria concorda que essas medidas rejeitadas na época, salvaram o capitalismo britânico nos primeiros anos após a Primeira Guerra².

O mesmo fenômeno se repetiu nos Estados Unidos, onde a Grande Depressão resultou em desemprego, queda na produção agrícola e industrial, falta de assistência, uso abusivo da mão-de-obra feminina e infantil, colocando em dúvida o modelo econômico americano. A revolta foi generalizada. No entanto, os privilegiados não estavam dispostos a aceitar medidas econômicas que poderiam aliviar a situação caótica da população. Coube a Franklin D. Roosevelt salvar o sistema econômico capitalista americano e, também, aqueles que o capitalismo mais favorecia, através de adaptações as quais tornaram a vida econômica mais estável e segura. Provavelmente isso não teria acontecido se os privilegiados e os mais beneficiados tivessem feito as coisas do seu jeito. A principal justificativa é que os afortunados não agem considerando o longo prazo, o esforço está concentrado no contentamento imediato.

Para compreender esse imediatismo na economia é preciso voltar no tempo, quando o livrecomércio começou a provocar as transformações do mundo no século XVIII. A Revolução Industrial, lenta no início e restrita à Grã-Bretanha e alguns países do leste europeu, conduziu o mundo para um caminho de constante expansão econômica, com níveis sem precedentes.

No final do século XX, o desenvolvimento econômico, com uma taxa de $2 \%$ de crescimento ao ano, tanto nos Estados Unidos como na Europa, foram considerados insuficientes para atender a demanda da sociedade. No entanto, durante a maior parte da história humana, para atingir um crescimento econômico de $2 \%$, não era em um ano, mas um esforço de décadas. As flutuações na economia eram mínimas, dependiam em maior parte, do clima que determinava os níveis de colheita; das incursões militares com expansões e pilhagens. O crescimento interno, contínuo da economia e a acumulação do capital, nessa época, era muito lento.

Um exemplo desse lento crescimento, é a análise dos dados comentado por Ormerod ${ }^{3}$, que durante mil anos, de 500 a 1500 d.C., quando o PIB cresceu em média 0,1\% ao ano. Isso quer dizer que no ano de 1500, o resultado econômico era entre duas vezes e meia a três vezes maior do que em 500. Apenas como

\footnotetext{
${ }^{2}$ GALBRAITH, John Kenneth. A cultura do contentamento. São Paulo: Pioneira, 1992, p. 2.

${ }^{3}$ ORMEROD, Paul. A morte da economia. São Paulo: Companhia das Letras, 1996, p. 20-21. Esses dados também estão disponíveis em: MADDISON, Angus. Phases of capitalist development. Oxford University Press, 1982.
}

\begin{tabular}{|c|c|c|c|c|c|}
\hline intuitio & $\begin{array}{c}\text { ISSN } \\
1983-4012\end{array}$ & Porto Alegre & Vol.11 - $\mathrm{N}^{\mathrm{o}} .1$ & $\begin{array}{l}\text { Julho } \\
2018\end{array}$ & p.105-114 \\
\hline
\end{tabular}


elemento comparativo, considerando as taxas efetivas de crescimento econômico, entre 1950 e 1970, as economias ocidentais cresceram, em termos percentuais, tanto quanto entre o período de 500 a 1500 . O desenvolvimento econômico começou a se tornar visível a partir de 1500, tanto que entre esse ano e 1700 a produção econômica no ocidente praticamente dobrou.

O crescimento econômico nesse período provocou profundas transformações na sociedade, praticamente impossível de reproduzir a extensão dessas mudanças, mas que podia ser observado por todos. Essa questão intrigou, sobretudo, os estudiosos clássicos da economia, pois o crescimento econômico implicou em alterações, tanto na economia como na sociedade. A amplitude desse crescimento não teve precedentes na história da humanidade e interferiu diretamente na explosão populacional e na melhoria dos padrões de vida da população da época.

Agora, também é oportuno, considerando a cultura do contentamento, fazer referência às pessoas e grupos de famílias pobres, muitas vezes abaixo do limite de pobreza, e aquelas ricas, que vivem em condições de conforto.

A renda desses últimos, muitas vezes garantida por meio de recursos públicos e privados: seguridade social, assistência médica mantida pelo governo ou empresas, subsídios agrícolas, seguros contra prejuízos decorrentes de falência de instituições financeiras ou bancos. Quando são destinadas às classes menos favorecidas, o apoio vem acompanhado por sérias desconfianças. Questiona-se a sua real necessidade e eficácia e, sobretudo os efeitos negativos que possam ocorrer sobre a moral e a disposição dos pobres para o trabalho. No entanto, essa preocupação não é extensiva ao apoio do governo para os mais favorecidos. Quando o rico recebe recurso público, ou é salvo de banco falido, não se considera lesado ou tem a moral prejudicada com o apoio governamental. As pessoas socialmente privilegiadas ao longo dos tempos formaram uma pequena minoria que, historicamente se tornaram a classe dirigente $\mathrm{e}$ dominante. Governam sob o manto da democracia, mas uma democracia que não contempla os mais pobres. É uma fraude dar ao capitalismo um nome mais ameno, o de sistema de mercado, com a intuição de diminuir a conotação de poder ao dono do capital. Não é comum afirmar que o poder capitalista está no indivíduo, que está na mão do administrador habilidoso. Quando há alusões ao sistema capitalista corporativo, os beneficiários do sistema, preferem normalmente utilizar o termo mercado. Como efeito comparativo o socialismo é visto com profunda ojeriza na cultura do contentamento, exceto para os indivíduos e as empresas financeiramente favorecidas.

\begin{tabular}{|c|c|c|c|c|c|}
\hline intuitio & $\begin{array}{c}\text { ISSN } \\
1983-4012\end{array}$ & Porto Alegre & Vol.11- $\mathrm{N}^{\mathrm{o}} .1$ & $\begin{array}{l}\text { Julho } \\
2018\end{array}$ & p.105-114 \\
\hline
\end{tabular}


A política e a cultura do "contentamento" no processo de globalização

Na concepção de Galbraith, a renda das pessoas de uma forma geral, define a cultura do contentamento ${ }^{4}$. Nesse aspecto, é importante considerar a atividade profissional, a classe social e a garantia da renda. Isso não quer dizer que não haja novas aspirações pessoais e unanimidade na compreensão política. Muitos tendo o suficiente, desejam mais, não conseguindo enxergar além do contentamento pessoal. A expressão de satisfação, é a afirmação de que não estão fazendo mais do que usufruir do justo merecimento. Por isso, surge objeção a tudo aquilo que possa interferir no seu conforto e segurança. Toda ameaça no sentido de diminuir, extirpar algum benefício ou aumentar imposto, provoca uma vigorosa insatisfação, amparado no argumento de que a fortuna é merecida, resultado do mérito pessoal.

A política governamental de empenhar obrigações financeiras no presente, que implicam no desenvolvimento e melhor qualidade de vida às gerações futuras, interfere no contentamento desses afortunados. Por exemplo, quando se aborda a questão ambiental: não se nega o problema, seria praticamente impossível, mas se protela qualquer tipo de ação. Muitas vezes o problema é encoberto por estudos e pesquisas duvidosas que procuram passar uma aparência de tranquilidade. São criadas comissões com intermináveis discussões, na maioria das vezes, adiando as medidas a serem tomadas, ou quando apenas algo simbólico é executado. O mesmo pode ser estendido ao que ocorre na infraestrutura. Praticamente todos admitem que estradas, aeroportos, portos, transporte público, precisam ser ampliados, modernizados com padrões de segurança e sustentabilidade. No entanto, existe resistência a qualquer gasto, cujo investimento beneficiará gerações futuras. A lógica do pensamento é que serão outros a se beneficiar no futuro com os impostos do presente. Qual a vantagem de pagar a conta de pessoas desconhecidas? Os exemplos deixam evidente a preferência pelas vantagens conservadoras e imediatas na cultura do contentamento. Essa cultura não parece se preocupar com as consequências a longo prazo.

Outra prática questionável na cultura do contentamento é a quantificação dos resultados econômicos. É preciso refletir sobre as limitações das abordagens econômicas, especialmente aquelas baseadas apenas na matemática aplicada. É claro que, se bem diligente tem suas vantagens, especialmente na organização e compreensão dos problemas e para proteger a economia do amadorismo. O lado negativo em empregar somente a matemática é quando utilizada apenas para analisar e comparar problemas humanos e sociais. Galbraith no seu ensaio de 1962, The language of economics (A linguagem da economia), apresentou ressalvas ao padrão determinante de teorizar a economia apenas através da matemática e econometria. Defende a posição de que é necessário levar em conta a informação de outras disciplinas e também a realidade política, não se prestando facilmente a tratamento altamente técnico e matemático. A crítica é especialmente dedicada aos economistas que têm a tendência de excluir da análise

${ }^{4}$ GALBRAITH, John Kenneth. A cultura do contentamento. São Paulo: Pioneira, 1992, p. 10-11.

\begin{tabular}{|c|c|c|c|c|c|}
\hline intuitio & $\begin{array}{c}\text { ISSN } \\
1983-4012\end{array}$ & Porto Alegre & Vol.11- $\mathrm{N}^{\mathrm{o}} .1$ & $\begin{array}{l}\text { Julho } \\
2018\end{array}$ & p.105-114 \\
\hline
\end{tabular}


econômica fatores mais difíceis de abordar quantitativamente, como por exemplo, a qualidade de vida e a satisfação dos mais necessitados.

Uma particularidade de contentamento dos mais ricos a ser ressaltada, é com a tolerância que os afortunados demonstram diante das grandes diferenças de renda. Galbraith chama atenção que essa disparidade não é assunto que provoca muita polêmica, pois segue uma observância genérica aceitável: “o preço para se prevenir qualquer agressão à própria renda é tolerar a renda maior dos demais" ${ }^{5}$. Portanto, distribuir a renda dos muito ricos, via impostos, implicaria em aumentar os impostos para aqueles que não são tão ricos. Ou seja, quando se aborda a questão dos impostos, aceita-se a desigualdade de forma velada, na qual o inimigo é comum: impostos mais altos para todos. Considerando as reivindicações das camadas menos favorecidas, isso consiste numa ameaça, pois os mais pobres geralmente dependem do governo para a obter a habitação subsidiada, a educação, o lazer, a saúde.

Por exemplo, o mercado não tem interesse em construir casas para os pobres, questão lamentavelmente negligenciada por praticamente todas as nações; o mesmo vale para a educação. Enquanto os pobres precisam recorrer às escolas públicas, os ricos pagam por suas próprias instituições de ensino; os pobres precisam de bibliotecas públicas, os ricos podem comprar os livros ou possuir sua própria biblioteca; os pobres necessitam de parques públicos para o lazer, enquanto os afortunados têm seus clubes particulares, campos de golfe, quadras de tênis; os hospitais públicos são o único recurso para as pessoas de baixa renda, enquanto os bem de vida tem acesso à hospitais particulares ou seguros-saúde. A reclamação dos afortunados é que eles pagam e os pobres recebem. Os ricos têm voz política, os pobres não, e o governo é tratado como ineficiente, incompetente, um fardo, destituído de função. Por outro lado, salvar instituições financeiras comerciais com recursos governamentais é visto como função do Estado, independente das extravagâncias financeiras criadas pelos executivos e pelas bandalheiras que tornaram a intervenção necessária. A cultura do contentamento tornou implícita a admissão de que, se uma instituição bancária for de grande porte, não será permitida a sua falência. A intervenção preventiva do governo não é permitida, é entendida como uma interferência específica no mercado, porém, a possibilidade de resgate é aceitável, necessária e bem-vinda. No entanto, se essas mesmas verbas empregadas no resgate desses bancos fossem aplicadas para melhorar a qualidade de vida dos mais necessitados, seriam consideradas um fardo insuportável e totalmente intolerável.

A formação de subclasse, resultante da política do contentamento, especialmente nas grandes cidades, é admitida. Porém, o que não se permite é que faça parte integrante do sistema econômico. Ela é útil e importante para os mais favorecidos por ser altamente funcional e, praticamente todos os países, em maior ou menor grau, possuem a sua. $\mathrm{O}$ crescimento econômico seria bem mais lento sem ela. Galbraith define o trabalho, considerando os cânones convencionais, como "algo agradável e gratificante. É algo no

${ }^{5}$ GALBRAITH, John Kenneth. A cultura do contentamento. São Paulo: Pioneira, 1992, p.16.

\begin{tabular}{|c|c|c|c|c|c|}
\hline intuitio & $\begin{array}{c}\text { ISSN } \\
1983-4012\end{array}$ & Porto Alegre & Vol.11- $\mathrm{N}^{\mathrm{o}} .1$ & $\begin{array}{l}\text { Julho } \\
2018\end{array}$ & p.105-114 \\
\hline
\end{tabular}


que todos os afortunados em sua profissão se deleitam em maior ou menor grau. Uma pessoa normal orgulha-se do seu trabalho"6. No entanto, na prática, o trabalho é em grande parte repetitivo, enfadonho, fatigante, maçante e socialmente degradante. Especialmente quando envolve serviços domésticos, agrícolas, industriais, no qual o custo da mão-de-obra interfere ou faz parte no preço final do produto. Essa lógica tende a desaparecer quando o custo da mão-de-obra e o preço do produto permanece dissociado, o que ocorre nos níveis de renda mais elevados, tornando o trabalho agradável e apreciado. Vale lembrar que os maiores salários são pagos para os trabalhos mais prestigiados e aprazíveis, realidade bem diferente para os que desenvolvem tarefas com conotação de inferioridade social, como varrer rua, recolher o lixo, fazer faxina.

Percebe-se aí que o significado do termo "trabalho" difere entre as classes. Enquanto para alguns é agradável, socialmente gratificante e bem remunerado, para outros é doloroso, desagradável, estafante e com baixa remuneração. O que se depreende dessa realidade, é que o trabalho continuará sendo uma necessidade iniludível da sociedade econômica e que os pobres são necessários para realizar as atividades que os ricos não querem realizar por considerar desagradável, desinteressante e de baixo prestígio. Em razão disso é preciso manter a subclasse permanentemente submissa.

Outro tópico que merece referência no tema da cultura do contentamento, é a grande organização empresarial, que é uma realidade do mundo globalizado, com suas complexidades e hierarquias. A cultura do mundo corporativo é visivelmente influenciada pela busca do contentamento e está associada à organização privada e governamental. Geralmente a organização privada é reconhecida como eficiente e dinâmica, enquanto que a pública considerada ineficiente, inepta e em muitas ocasiões arrogante.

Nas organizações de grande porte, o que se percebe é que o propósito comum está bem definido. Na grande companhia é designada como política da empresa, enquanto na organização governamental, é chamada de política oficial. O contentamento individual passa pela aceitação desses propósitos formalmente instituídos. Os que manifestam resistências a essas políticas, não encontram espaço, pois são consideradas atitudes adversas para o sucesso da corporação. O fundamental é aceitar a política institucional, ser dócil e trabalhar em razão da meta comum, tornando-se um excelente membro da equipe. Em outros termos, trata-se de submeter ao regime determinante dessas grandes organizações, que trabalham com compromissos institucionais, a fim de atingir um agir instituído. Para Galbraith, "essa submissão, por sua vez, favorece a aceitação pessoal e a harmonia social, sendo fundamental para a cultura do contentamento e um poderoso condicionador dentro dela. $\mathrm{O}$ bom funcionário da organização é aquele contente com o que existe" ${ }^{77}$. Assim, tanto a vida particular como a pública são controlados.

${ }^{6}$ GALBRAITH, John Kenneth. A cultura do contentamento. São Paulo: Pioneira, 1992, p. 20.

${ }^{7}$ GALBRAITH, John Kenneth. A cultura do contentamento. São Paulo: Pioneira, 1992, p. 45.

\begin{tabular}{|c|c|l|l|l|l|}
\hline intuitio & $\begin{array}{c}\text { ISSN } \\
1983-4012\end{array}$ & Porto Alegre & Vol.11- $\mathrm{N}^{\circ} .1$ & $\begin{array}{l}\text { Julho } \\
2018\end{array}$ & p.105-114 \\
\hline
\end{tabular}


A organização moderna, também, colabora com aquilo que é mais aprazível no contentamento, que é a diminuição e o valor do próprio pensamento. A tendência nos altos escalões das organizações, quando o pensar é inevitável, é comum não enfrentar o problema, mas o de delegar para um subordinado. Essa passa para um assistente e o processo de delegação prossegue. " $O$ forte da cultura da organização está em transferir problema para os outros - em esquivar-se do esforço mental pessoal e da responsabilidade", tornando uma atitude generalizada, transferindo para o outro a preocupação. Ou, como Galbraith diz de forma muito clara e conclusiva na sequência, "no mundo das grandes organizações, os problemas não são resolvidos; eles são repassados adiante"8. As grandes organizações, públicas e privadas, estão condicionadas para a cultura do contentamento, ou seja, para o conforto imediatista.

O que provoca ameaça ao contentamento, é a instabilidade, a recessão no capitalismo, cujos efeitos mais imediatos são sentidos nos níveis de emprego, sobre o salário e sobre o lucro das empresas. É consonância, nessa cultura, que desde a Grande Depressão dos anos 30, os governos devem controlar as manifestações de instabilidade na economia com ações políticas macroeconômicas. No entanto, esse consenso não chega a ser unanime, porque todo início de recessão traz consigo a previsão dos economistas de que será rápida e se corrigirá a si própria. A mensagem é que tudo se resolverá por si mesmo ao longo do tempo, com a ideia de que o longo prazo jamais chegue. Para esse tipo de argumento, a frase mais citada de John Maynard Keynes, faz todo sentido: "a longo prazo estaremos todos mortos". Assim, continuando a oratória teológica do contentamento: como é preciso ter fé em Deus, é preciso ter fé no mercado. Aliás, atualmente, na era do contentamento, a fé no mercado parece estar mais forte do que antes, ou maior do que qualquer crença.

As lideranças políticas que acomodam a política moderna, são em grande parte, raras são as vozes dissonantes, produto do sistema dominante, políticos alinhados com os bens de vida, cuja meta é não mexer com a comunidade do contentamento. Atualmente, a democracia é para os favorecidos e os satisfeitos. Os detentores do poder econômico monopolizam o contexto político. Isso é facilmente percebido quando se avaliam políticos que realmente estão preocupados, em representar os pobres, os favelados, os desgraçados. A democracia do contentamento, como já foi dito anteriormente, prioriza a política do imediatismo, da acomodação do pensamento econômico e político.

\section{III}

Caso nada for feito, o que se deslumbra no horizonte da cultura do contentamento, é a manutenção do incentivo de uma boa renda para os ricos e aos fluentes e, por outro lado, a conservação da pobreza aos pobres. Evidente, que isso é dito com muita discrição. Então, como será o futuro? As mudanças

${ }^{8}$ GALBRAITH, John Kenneth. A cultura do contentamento. São Paulo: Pioneira, 1992, p. 45.

\begin{tabular}{|c|c|l|l|l|l|}
\hline intuitio & $\begin{array}{c}\text { ISSN } \\
1983-4012\end{array}$ & Porto Alegre & Vol.11- No.1 & $\begin{array}{l}\text { Julho } \\
2018\end{array}$ & p.105-114 \\
\hline
\end{tabular}


necessárias para a alteração do rumo, deverão partir da própria estrutura mantenedora do contentamento. Fatos que contestassem de forma radical a estrutura vigente e a obrigassem a condução de uma nova visão da sociedade. A esperança estará depositada no surgimento de líderes e legisladores, como já ocorreu em outros momentos históricos. Deverá ser resultado de um movimento forte que provocasse um abalo radical na cultura do contentamento ${ }^{9}$, desafiando o senso de bem-estar dos afortunados, liderado sobretudo pelos menos favorecidos, os da camada de baixo da sociedade. Galbraith, por sua vez, entende que existe três maneiras para mudar essa cultura: "um grande cataclismo econômico, uma ação militar desastrosa decorrente de alguma iniciativa mal pensada no cenário internacional, e a erupção de uma subclasse furiosa" $" 10$.

A intervenção do estado na era do contentamento, quando aparece, é para atender os interesses dos afortunados e, limitado quando o problema são os pobres. É improvável que ocorra uma intervenção governamental para aliviar o sofrimento dos pobres, diminuir a pobreza e aumentar o emprego. Geralmente o discurso é que a recuperação da economia será rápida, autocorretiva e que os descontentes devem aceitar pacificamente o seu destino, com o controle nas mãos dos mais afortunados. Para acabar com a era do contentamento será necessário que essa crença seja posta abaixo, pois um fato é fundamental: praticamente toda ação que possa remediar ou tranquilizar, envolve a relação entre o cidadão e o estado. Portanto, no capitalismo moderno, resultado de uma economia mista, é fundamental envolver as ações do estado. A atuação do estado precisa corrigir a situação atual da fuga da realidade e se tornar igualmente necessário, tanto para os satisfeitos como para os excluídos e à margem. Não é mais possível deixar a estabilidade da economia, a geração de empregos, somente nas mãos de Deus e do laissez faire.

\section{Referências}

GALBRAITH, John Kenneth. A cultura do contentamento. São Paulo: Pioneira, 1992. . O novo estado industrial. São Paulo: Abril Cultural, 1982. . Uma visão de Galbraith sobre pessoas, políticos, poder militar e as artes. São Paulo: Pioneira, 1989. . American capitalismo: the concepto f coutervailing power. Boston: H Miffilin, 1956. Moeda: de onde veio, para onde foi. São Paulo: Pioneira, 1997. Capitalismo. Rio de Janeiro: Zahar, 1964. . A era da incerteza. São Paulo: Pioneira, 1991. . Anatomia do poder. São Paulo: Pioneira, 1989. A economia e arte da controvérsia. Rio de Janeiro: Fundo de cultura, 1959. Economia, paz e humor. São Paulo: Círculo do livro, 1972. A sociedade justa: uma perspectiva humana. Rio de Janeiro: Campus, 1996. Uma breve história da euforia financeira. São Paulo: Pioneira, 1992. . O desenvolvimento econômico em perspectiva. Rio de Janeiro: Fundo de cultura, 1962. The great crash: 1929. Harmondsworth: Penquin, 1971.

${ }^{9}$ Um fato que chacoalhou a economia e a política do contentamento no passado, já exposto anteriormente, e que resultou em mudanças, por exemplo, foi a Grande Depressão nos EUA.

${ }^{10}$ GALBRAITH, John Kenneth. A cultura do contentamento. São Paulo: Pioneira, 1992, p. 96.

\begin{tabular}{|c|c|c|c|c|c|}
\hline intuitio & $\begin{array}{c}\text { ISSN } \\
1983-4012 \\
\end{array}$ & Porto Alegre & Vol.11 - N $\mathrm{N}^{\mathrm{o}} .1$ & $\begin{array}{l}\text { Julho } \\
2018 \\
\end{array}$ & p. $105-114$ \\
\hline
\end{tabular}


A política e a cultura do "contentamento" no processo de globalização

. A economia e o objetivo público. São Paulo: Martins, 1975.

. O pensamento econômico em perspectiva: uma história crítica. São Paulo: Pioneira, 1989.

. A economia e o interesse público. São Paulo: Pioneira, 1988.

. A sociedade afluente. São Paulo: Pioneira, 1987.

. Crônicas de um eterno liberal. Rio de Janeiro: Fronteira, 1980.

. Uma viagem pelo tempo econômico: um relato em primeira mão. São Paulo: Pioneira, 1994.

. Capitalismo, comunismo \& coexistência: de um passado amargo a esperanças melhores. São Paulo:

Pioneira, 1988.

ORMEROD, Paul. A morte da economia. São Paulo: Companhia das Letras, 1996.

STIGLITZ, Joseph E. A globalização e seus malefícios. São Paulo: Futura, 2002.

\begin{tabular}{|l|c|l|l|l|l}
\hline intuitio & $\begin{array}{c}\text { ISSN } \\
1983-4012\end{array}$ & Porto Alegre & Vol.11- $\mathrm{N}^{\circ} .1$ & $\begin{array}{l}\text { Julho } \\
2018\end{array}$ & p.105-114 \\
\hline
\end{tabular}

